\title{
Substrate temperature and electron fluence effects on metallic films created by electron beam induced deposition
}

\author{
Samantha G. Rosenberg \\ Department of Chemistry, Johns Hopkins University, Baltimore, Maryland 21218 \\ Kees Landheer and Cornelis W. Hagen \\ Delft University of Technology, Faculty of Applied Sciences, Lorentzweg 1, 2628CJ, Delft, The Netherlands \\ D. Howard Fairbrother ${ }^{a}$ ) \\ Department of Chemistry, Johns Hopkins University, Baltimore, Maryland 21218
}

(Received 14 June 2012; accepted 20 August 2012; published 12 September 2012)

\begin{abstract}
Using three different precursors $\left[\mathrm{MeCpPtMe}_{3}, \mathrm{Pt}\left(\mathrm{PF}_{3}\right)_{4}\right.$, and $\left.\mathrm{W}(\mathrm{CO})_{6}\right]$, an ultra-high vacuum surface science approach has been used to identify and rationalize the effects of substrate temperature and electron fluence on the chemical composition and bonding in films created by electron beam induced deposition (EBID). X-ray photoelectron spectroscopy data indicate that the influence of these two processing variables on film properties is determined by the decomposition mechanism of the precursor. For precursors such as $\mathrm{MeCpPtMe}_{3}$ that decompose during EBID without forming a stable intermediate, the film's chemical composition is independent of substrate temperature or electron fluence. In contrast, for $\mathrm{Pt}\left(\mathrm{PF}_{3}\right)_{4}$ and $\mathrm{W}(\mathrm{CO})_{6}$, the initial electron stimulated deposition event in EBID creates surface bound intermediates $\operatorname{Pt}\left(\mathrm{PF}_{3}\right)_{3}$ and partially decarbonylated $\mathrm{W}_{x}(\mathrm{CO})_{y}$ species, respectively. These intermediates can react subsequently by either thermal or electron stimulated processes. Consequently, the chemical composition of EBID films created from either $\mathrm{Pt}\left(\mathrm{PF}_{3}\right)_{4}$ or $\mathrm{W}(\mathrm{CO})_{6}$ is influenced by both the substrate temperature and the electron fluence. Higher substrate temperatures promote the ejection of intact $\mathrm{PF}_{3}$ and $\mathrm{CO}$ ligands from $\mathrm{Pt}\left(\mathrm{PF}_{3}\right)_{3}$ and $\mathrm{W}_{x}(\mathrm{CO})_{y}$ intermediates, respectively, improving the film's metal content. However, reactions of $\mathrm{Pt}_{(}\left(\mathrm{PF}_{3}\right)_{3}$ and $\mathrm{W}_{x}(\mathrm{CO})_{y}$ intermediates with electrons involve ligand decomposition, increasing the irreversibly bound phosphorous content in films created from $\mathrm{Pt}\left(\mathrm{PF}_{3}\right)_{4}$ and the degree of tungsten oxidation in films created from $\mathrm{W}(\mathrm{CO})_{6}$. Independent of temperature effects on chemical composition, elevated substrate temperatures $\left(>25^{\circ} \mathrm{C}\right)$ increased the degree of metallic character within EBID deposits created from $\mathrm{MeCpPtMe} 3$ and $\mathrm{Pt}\left(\mathrm{PF}_{3}\right)_{4}$. (C) 2012 American Vacuum Society. [http://dx.doi.org/10.1116/1.4751281]
\end{abstract}

\section{INTRODUCTION}

Electron beam induced decomposition (EBID) is a resistless, low vacuum deposition technique that uses a focused electron beam to create $3 \mathrm{D}$ nanostructures or patterns. ${ }^{1-4}$ To create metal containing EBID materials, deposition is accomplished by irradiating a surface with a focused electron beam in a constant partial pressure of a sufficiently volatile precursor, typically in an electron microscope. Deposition occurs when transiently adsorbed precursors undergo electron stimulated decomposition and form nonvolatile products. Due to the comparative ease with which electron beams can be focused and manipulated, EBID possesses a unique and attractive combination of capabilities for prototyping well-defined, three-dimensional nanostructures, and the flexibility to deposit on nonplanar surfaces.

Despite its ability to generate a range of different nanostructures, EBID is not without its shortcomings. One of the major limitations of EBID is that the metal containing nanostructures often contain unacceptable levels of organic contamination (predominantly carbon) that limit the range of useful applications for the EBID material. These impurities

${ }^{\text {a)} E l e c t r o n i c ~ m a i l: ~ h o w a r d f @ j h u . e d u ~}$ are a consequence of the fact that in addition to depositing metal atoms, the EBID process also decomposes the ligand architecture of the precursor and this leads to the formation of nonvolatile organic contaminants. The presence of these organic contaminants causes EBID structures to have higher resistance values compared to bulk metals. For example, the resistivity reported for metal nanostructures created from a common platinum EBID precursor trimethyl(methylcyclopentadienyl)platinum $\left(\mathrm{MeCpPtMe}_{3}\right)$ have been measured at $1.5 \times 10^{3} \mu \Omega \mathrm{cm}$, compared to the resistivity of pure platinum $(10.62 \mu \Omega \mathrm{cm}) .^{5}$

In an attempt to remove or at least reduce the level of contamination in EBID materials a number of in situ or postdeposition purification techniques have been developed. Post-deposition purification techniques capable of reducing the carbon content include simply annealing the substrate or exposing deposits to oxygen while heating the substrate. ${ }^{6,7}$ In situ techniques focus mainly on changing the electron beam parameters, namely, the spot size, dwell time, or current density. ${ }^{8-12}$ Another in situ approach to improve purity has involved performing EBID on a heated substrate. ${ }^{8}$ For example, using the $\mathrm{Me}_{2} \mathrm{Au}(\mathrm{tfac})$ precursor Koops et al. showed that depositions carried out at a substrate temperature of $80^{\circ} \mathrm{C}$ resulted in EBID materials with lower resistivity 
compared to deposits created on substrates maintained at room temperature. ${ }^{13}$ The lower resistivity was ascribed to the fact that the atomic percentage of $\mathrm{Au}$ in the deposits increased significantly when the substrate temperature during deposition was increased (1-15 at. \% at room temperature vs 70 at. \% at $80^{\circ} \mathrm{C}$ ). In another example, Wang et al. showed that for EBID films created from $\mathrm{Pt}\left(\mathrm{PF}_{3}\right)_{4}$ in an Auger electron spectrometer the $(\mathrm{Pt} / \mathrm{Pt}+\mathrm{P})$ atomic percent increased systematically as the substrate temperature increased from $25^{\circ} \mathrm{C}$ to $120^{\circ} \mathrm{C}^{14}$ More recently, Mulders et al. performed a systematic temperature dependent study on a range of EBID precursors: $\mathrm{W}(\mathrm{CO})_{6}, \mathrm{TEOS}, \mathrm{MeCpPtMe}_{3}, \mathrm{Co}(\mathrm{CO})_{3} \mathrm{NO}, \mathrm{Co}_{2}(\mathrm{CO})_{8}$, and $\mathrm{Me}_{2} \mathrm{Au}(\mathrm{acac})$. This study revealed that increases in metallic content can occur when the substrate temperature was increased, although the importance of this processing variable depended on the precursor. ${ }^{15}$ For example, TEOS and $\mathrm{MeCpPtMe}_{3}$ showed no increase in metallic content when the substrate temperature was increased. In contrast, the metallic content of EBID films created from $\mathrm{W}(\mathrm{CO})_{6}$ increased from 36.7 at. $\%$ to 59.2 at. $\%$ when the substrate temperature was increased from $25^{\circ} \mathrm{C}$ to $280^{\circ} \mathrm{C}$. Collectively, these results on $\mathrm{W}(\mathrm{CO})_{6}$ and $\mathrm{Pt}\left(\mathrm{PF}_{3}\right)_{4}$ strongly suggest that thermal as well as electron stimulated reactions can also contribute to the overall decomposition process and thus the ultimate chemical composition in the deposit. However, the underlying reactions responsible for these temperature dependent variations in film composition have yet to be elucidated.

In the past several years, we have focused on developing a molecular level understanding of the EBID process by studying the underlying surface chemistry that occurs when precursor compounds (predominantly organometallic) adsorbed on solid substrates at low temperatures $\left(<-110^{\circ} \mathrm{C}\right)$ are exposed to electron irradiation in an ultra-high vacuum (UHV) environment. In contrast, typical EBID structures are created in the presence of a partial pressure of precursor molecules using a substrate whose temperature is at or above room temperature. Once deposited these nanostructures are typically characterized post-deposition by scanning electron microscopy (SEM) or transmission electron microscopy, and compositionally through energy-dispersive $\mathrm{x}$-ray spectroscopy. In contrast, our UHV surface science approach enables us to study changes in composition and bonding in situ during the deposition process by using a combination of complementary analytical techniques such as X-ray photoelectron spectroscopy (XPS) and mass spectrometry (MS). XPS, in particular, has proved particularly useful by virtue of its ability to inform on changes in both composition and bonding within the film. Using this UHV surface science approach we have studied the electron stimulated reactions of several precursors: $\mathrm{MeCpPtMe}_{3},{ }^{16} \mathrm{Me}_{2}$ Auacac, ${ }^{17} \mathrm{Cp}_{2} \mathrm{Ni}^{1},{ }^{18} \mathrm{Cu}(\mathrm{hfac})_{2},{ }^{18}$ $\mathrm{Pt}\left(\mathrm{PF}_{3}\right)_{4},{ }^{19}$ and $\mathrm{W}(\mathrm{CO})_{6} .{ }^{20}$ Results from these studies have revealed the importance that ligand architecture plays in determining the electron stimulated decomposition pathways as well as the nature and concentration of the residual organic contaminants.

In the present study we have expanded the scope of these studies to probe the interplay that exists between substrate temperature and electron fluence in terms of the effect that these two variables have on the composition and metallic content of EBID films created under UHV conditions from $\mathrm{MeCpPtMe}_{3}, \mathrm{Pt}\left(\mathrm{PF}_{3}\right)_{4}$, and $\mathrm{W}(\mathrm{CO})_{6}$. The choice of these three molecules was predicated on their widespread use by the EBID community as precursors, and our understanding of the purely electron stimulated decomposition process. ${ }^{7,8,10,11,16,19,21-32}$ In addition, our results can be compared and benchmarked against compositional data that already exist from previous EBID studies where deposition was accomplished under more typical conditions. Our experimental approach involved exposing nanometer thick films of parent precursor molecules to different electron fluences. After electron exposure the films were annealed in stages while their composition and bonding was tracked in situ with XPS. In this way, we were able to probe the effect of substrate temperature on different surface bound species created by electron stimulated reactions. Results from these studies have also helped us to elucidate the bond breaking processes that are responsible for the effects that changing substrate temperature have on the chemical composition of EBID materials created from these three precursors.

\section{EXPERIMENT}

The UHV chamber $\left(P_{\text {base }}<5 \times 10^{-9}\right.$ Torr $)$ and its capabilities have been described previously. ${ }^{16,31}$ In essence, experiments involved depositing nanometer thick films of precursor molecules onto cooled substrates under UHV conditions, exposing these films to a known electron fluence followed by annealing. Brief descriptions of the various experimental elements are provided in Secs. II A-II F.

\section{A. Precursors}

Three different EBID precursors were used: $\mathrm{MeCpPtMe}_{3}$ (CAS 94442-22-5, Aldrich) is a low vapor pressure solid; $\mathrm{Pt}\left(\mathrm{PF}_{3}\right)_{4}$ (CAS 19529-53-4, Strem Chemicals, Inc.) is a high vapor pressure liquid; $\mathrm{W}(\mathrm{CO})_{6}$ (CAS 14040-11-0, Strem Chemicals, Inc.) is a low vapor pressure solid. Each precursor was attached to a stainless steel gas manifold which was coupled to the UHV chamber via a leak valve. The manifold was evacuated and the precursor purified by direct pumping $\left[\mathrm{MeCpPtMe}_{3}\right.$ and $\left.\mathrm{W}(\mathrm{CO})_{6}\right]$ or by a series of freeze-pump thaw cycles $\left[\mathrm{Pt}\left(\mathrm{PF}_{3}\right)_{4}\right]$. The gas manifold was then filled with a partial pressure of the precursor $\left[\right.$ for $\mathrm{W}(\mathrm{CO})_{6}$ this required heating the compound to $75^{\circ} \mathrm{C}$ ]. The purity of the gases was routinely checked by a quadrupole mass spectrometer housed within the UHV chamber.

\section{B. Substrates}

For $\mathrm{MeCpPtMe}_{3}$ and $\mathrm{W}(\mathrm{CO})_{6}$ a polycrystalline Au substrate was used, while an amorphous carbon $(a: \mathrm{C})$ substrate was used for experiments involving $\mathrm{Pt}\left(\mathrm{PF}_{3}\right)_{4}$. This choice of substrates was governed by the general lack of chemical reactivity and ease of cleaning. Each substrate was mounted onto a manipulator with the capability for $x y z$ translation and rotation, as well as the ability to be liquid nitrogen cooled and resistively heated. In selected instances experiments were repeated on different substrates to verify that observed 
phenomena were not influenced by the substrate. For example, the temperature dependent shifts in the $\mathrm{Pt}(4 f)$ peak positions observed for $\mathrm{MeCpPtMe}_{3}$ on $\mathrm{Au}$ substrates were also observed on $a$ :C substrates.

\section{Analysis}

XPS was performed with a Physical Electronics 5400 system using $\mathrm{Mg} \mathrm{K} \alpha$ x rays $(h \nu=1253.6 \mathrm{eV})$. All x-ray photoelectron (XP) spectra were deconvoluted with commercially available software (CASA XPS); peak positions obtained for $\mathrm{MeCpPtMe}_{3}$ and $\mathrm{W}(\mathrm{CO})_{6}$ films deposited on Au substrates were aligned to the $\mathrm{Au}\left(4 f_{7 / 2}\right)$ peak at $84 \mathrm{eV}$, while all $\mathrm{Pt}\left(\mathrm{PF}_{3}\right)_{4}$ films deposited on $a$ : $\mathrm{C}$ were aligned to the $\mathrm{C}(1 s)$ peak at $284.6 \mathrm{eV} .^{33} \mathrm{XP}$ spectra were measured with a step size of $0.125 \mathrm{eV}$ and at pass energies of 89 and $22 \mathrm{eV}$. Data obtained at $22 \mathrm{eV}$ pass energy were used to determine the exact peak positions and spectral envelopes, while experiments performed at $89 \mathrm{eV}$ pass energy were used to quantify fractional coverages of different elements.

\section{Creating films}

Experiments involved first creating nanometer scale thick films of EBID precursors under UHV conditions. Nanometer scale thick films were created for $\mathrm{Pt}\left(\mathrm{PF}_{3}\right)_{4}(0.3 \mathrm{~nm})$, $\mathrm{MeCpPtMe}_{3}(2.5 \mathrm{~nm})$, and $\mathrm{W}(\mathrm{CO})_{6}(1.5 \mathrm{~nm})$. These film thicknesses were determined based on the compound's molecular structure to correspond to an average coverage of 1-2 monolayers. Each film was created by leaking the precursor into the chamber through the UHV compatible leak valve and onto a cooled $\left(-110^{\circ} \mathrm{C}\right) 1 \mathrm{~cm}^{2}$ substrate. The film thickness was determined by measuring the signal attenuation from the substrate's photoelectrons using XPS. For both of the $\mathrm{C}(1 s)$ and $\mathrm{Au}(4 f)$ photoelectrons, an inelastic mean free path of $2.0 \mathrm{~nm}$ was used. ${ }^{34}$

\section{E. Electron source}

Once the film's thickness and composition had been determined it was exposed to a known electron fluence. As described previously, a commercial flood gun (Specs FG 15/40) was used as a broad beam electron source. ${ }^{16,17}$ Prior to use, the electron gun was thoroughly outgassed and characterized by a Faraday cup to ensure that the sample surface was subjected to a relatively uniform electron fluence. The incident electron energy was calculated from the sum of the electron energy generated by the flood gun $(480 \mathrm{eV})$ and a positive bias $(+20 \mathrm{~V})$ applied to the substrate to attract the secondary electrons emitted during irradiation. Thus, the total electron energy used throughout this study was $500 \mathrm{eV}$. The energy of the electrons produced by the flood gun was also characterized by the hemispherical electron analyzer. The target current was held at $5 \mu \mathrm{A}$, and was monitored by a picoammeter connected to the substrate through the heating rods. For all experiments electron irradiation is reported in terms of fluence $\left(\mathrm{e}^{-} / \mathrm{cm}^{2}\right)$.

\section{F. Annealing protocol}

Once the film had been irradiated by a known electron fluence the substrate temperature was increased from $-110^{\circ} \mathrm{C}$ in incremental steps to a final temperature $>200^{\circ} \mathrm{C}$, and the change in the film's composition and bonding was monitored by XPS. For films created with W(CO) 6 and $\mathrm{Pt}\left(\mathrm{PF}_{3}\right)_{4}$, the temperature was increased to the desired value and then held at that point for $10 \mathrm{~s}$; for films created from $\mathrm{MeCpPtMe}_{3}$ the substrate temperature was maintained for $25 \mathrm{~s}$. After annealing, the film was allowed to cool back to $-110^{\circ} \mathrm{C}$ and an XP spectrum was taken. The film was then heated again to a higher temperature and the procedure repeated. At the conclusion of each set of annealing experiments the surface was cleaned by $\mathrm{Ar}^{+}$ion bombardment.

\section{RESULTS AND DISCUSSION}

The present study uses an UHV surface science approach as a route to understand the impact of substrate temperature and electron fluence on the chemical composition and bonding in EBID structures created from three different precursors. The effect of these two variables was probed by first electron irradiating the molecular precursor under UHV conditions at low temperatures before annealing. By varying the initial electron fluence prior to annealing, the thermal reactions of different species produced by electron induced decomposition of the parent molecules can be interrogated. This approach is facilitated by the temperature independent nature of electron stimulated processes, providing a rationale for our experimental methodology where these two processing variables are independently varied. To ensure that results from our studies are relevant to typical EBID experiments performed in the presence of a constant partial pressure of precursor molecules it is necessary to ensure that all of the parent molecules $\left[\mathrm{MeCpPtMe}_{3}, \mathrm{Pt}\left(\mathrm{PF}_{3}\right)_{4}\right.$, and $\left.\mathrm{W}(\mathrm{CO})_{6}\right]$ have been depleted by electron stimulated reactions prior to annealing. This step ensures that the effect of substrate temperature provides information only on the fate of those nonvolatile species deposited on the surface by electron beam reactions with the precursor. To accomplish this goal we have taken advantage of information acquired in our previous UHV studies, ${ }^{16,19}$ which indicate that the initial electron induced reaction of the three precursor molecules $\left[\mathrm{MeCpPtMe}_{3}, \mathrm{Pt}\left(\mathrm{PF}_{3}\right)_{4}\right.$, and $\left.\mathrm{W}(\mathrm{CO})_{6}\right]$ involves the ejection of gas phase $\mathrm{CH}_{4}, \mathrm{PF}_{3}$, and $\mathrm{CO}$ species, respectively. In typical EBID experiments this initial electron stimulated reaction corresponds to the electron stimulated deposition event that converts the transiently adsorbed precursor molecule into a surface bound species.

\section{A. $\mathrm{MeCpPtMe}_{3}$}

Our previous studies have shown that the electron stimulated deposition of $\mathrm{MeCpPtMe}_{3}$ proceeds via the cleavage of a single $\mathrm{Pt}-\mathrm{CH}_{3}$ bond and the ejection of methane accompanied by a decrease in the $\operatorname{Pt}\left(4 f_{7 / 2}\right)$ binding energy as the $\mathrm{Pt}(\mathrm{IV})$ species in the parent molecule are reduced. ${ }^{16}$ Thus, all of the annealing experiments were conducted on films initially exposed to an electron fluence in excess of the value required to convert all of the parent species to products as judged by, (1) spectral deconvolution of the $\operatorname{Pt}(4 f)$ region, and (2) the completion of methane production as judged by MS. 
Figure 1(a) shows the variation in chemical composition of three $\mathrm{MeCpPtMe}_{3}$ films initially exposed to electron fluences of $3.37 \times 10^{+16} \mathrm{e}^{-} / \mathrm{cm}^{2}$ (triangles), $1.042 \times 10^{+17} \mathrm{e}^{-} /$ $\mathrm{cm}^{2}$ (squares), $2.75 \times 10^{+17} \mathrm{e}^{-} / \mathrm{cm}^{2}$ (circles) and then annealed from $-110^{\circ} \mathrm{C}$ to $367^{\circ} \mathrm{C}$. These three electron fluences include values that are just slightly larger than the fluence necessary to cleave all of the $\mathrm{Pt}-\mathrm{CH}_{3}$ bonds within the adsorbate layer $\left(3.25 \times 10^{+16} \mathrm{e}^{-} / \mathrm{cm}^{2}\right)$ and an electron fluence that is well in excess of this point. ${ }^{16}$ Analysis of Fig. 1(a) reveals that regardless of the electron fluence the film's composition is $\approx 90 \%$ carbon and $\approx 10 \%$ platinum. The slight (1-2\%) increase in the carbon content of films exposed to a larger electron fluence can reasonably be ascribed to carbon deposition from hydrocarbons present in the UHV background and/or created by the electron gun.
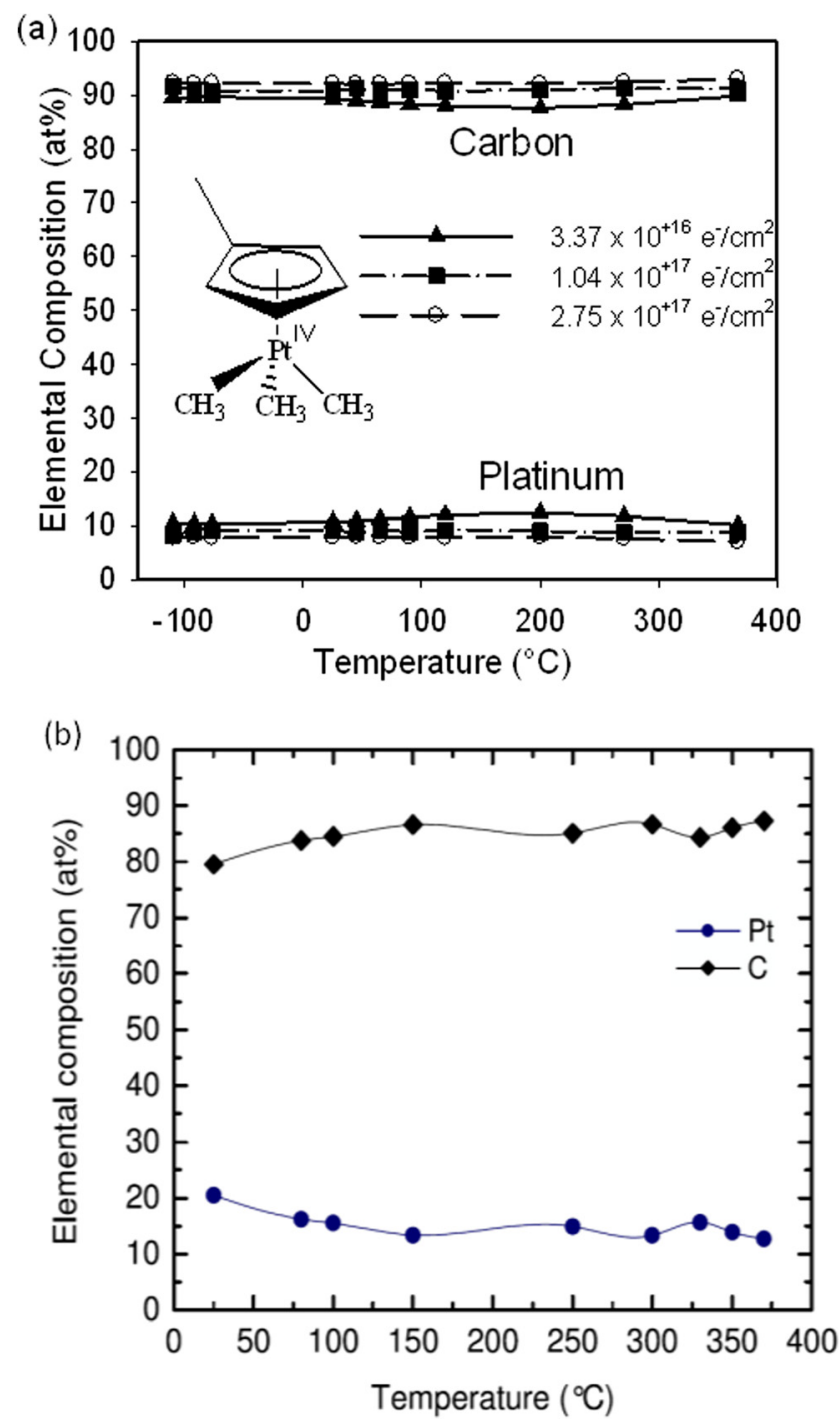

FIG. 1. (Color online) (a) Effect of substrate temperature on the elemental composition of $2.5 \mathrm{~nm}$ thick films of $\mathrm{MeCpPtMe}_{3}$ exposed to electron fluences of $3.37 \times 10^{+16} \mathrm{e}^{-} / \mathrm{cm}^{2}$ (triangle), $1.042 \times 10^{+17} \mathrm{e}^{-} / \mathrm{cm}^{2}$ (square), and $2.75 \times 10^{+17} \mathrm{e}^{-} / \mathrm{cm}^{2}$ (circle). Films were exposed to electron irradiation at $-110^{\circ} \mathrm{C}$ and then heated in stages up to $367^{\circ} \mathrm{C}$. (b) Composition of EBID films created in an electron microscope using $\mathrm{MeCpPtMe}_{3}$ as a function of the substrate temperature. Reprinted with permission from Mulders, Belova, and Riazanova, Nanotechnology 22, 055302 (2011).
Regardless of the initial electron fluence, Fig. 1(a) shows that the film's composition remains invariant to the substrate temperature in the range $-110^{\circ} \mathrm{C}$ to $367^{\circ} \mathrm{C}$. This indicates that following the initial $\mathrm{Pt}-\mathrm{CH}_{3}$ bond cleavage event, no volatile carbon-containing species are left within the deposit.

Although the Pt/C ratio in films created from $\mathrm{MeCpPtMe}_{3}$ does not change with increasing electron fluence and/or temperature, we did observe a systematic decrease in the binding energy of the $\mathrm{Pt}(4 f)$ peaks at substrate temperatures in excess of $50{ }^{\circ} \mathrm{C}$. An example is shown in Fig. 2 for a $\mathrm{MeCpPtMe}_{3}$ film initially exposed to an electron fluence of $3.37 \times 10^{+16}$ $\mathrm{e}^{-} / \mathrm{cm}^{2}$; similar trends were observed for all films regardless of the initial electron fluence or the nature of the substrate (Au or $a$ :C). Thus, Fig. 2 shows that the $\mathrm{Pt}\left(4 f_{7 / 2}\right)$ peak position remains constant at $\approx 72.4 \mathrm{eV}$ for substrate temperatures $<50{ }^{\circ} \mathrm{C}$, but then decreases systematically to $71.3 \mathrm{eV}$ as the temperature is increased from $50^{\circ} \mathrm{C}$ to $367^{\circ} \mathrm{C}$. This final value of the $\operatorname{Pt}\left(4 f_{7 / 2}\right)$ peak position is close to the reported value for metallic platinum, $71.1 \mathrm{eV} .{ }^{16}$ The implications of this change in $\operatorname{Pt}(4 f)$ peak position upon thermal annealing are described later in Sec. IV.

\section{B. $\mathrm{Pt}\left(\mathrm{PF}_{3}\right)_{4}$}

Previously we have shown that the electron stimulated deposition of $\mathrm{Pt}\left(\mathrm{PF}_{3}\right)_{4}$ is initiated by the cleavage of a single $\mathrm{Pt}-\mathrm{PF}_{3}$ bond, the ejection of one $\mathrm{PF}_{3}$ ligand, and the formation of a surface bound $\mathrm{Pt}\left(\mathrm{PF}_{3}\right)_{3}$ intermediate. ${ }^{19}$ More prolonged electron exposures cause electron stimulated P-F bond cleavage within the $\mathrm{Pt}\left(\mathrm{PF}_{3}\right)_{3}$ intermediate, the loss of fluorine and the creation of coordinately unsaturated phosphorous atoms which react rapidly with any residual water vapor, generating an amorphous film that contains platinum, phosphorous, fluorine, and oxygen atoms $\left(\mathrm{PtP}_{3} \mathrm{~F}_{x} \mathrm{O}_{y}\right)$. The effects of electron fluence on adsorbed $\mathrm{Pt}\left(\mathrm{PF}_{3}\right)_{4}$ molecules are summarized on the left hand side of Fig. 3 . To ensure that annealing experiments performed as part of the present investigation were conducted on films where all of the parent $\mathrm{Pt}\left(\mathrm{PF}_{3}\right)_{4}$ molecules had decomposed, the initial electron fluence was in excess of the value required to create the $\mathrm{Pt}\left(\mathrm{PF}_{3}\right)_{3}$ intermediate $\left(2.39 \times 10^{+15} \mathrm{e}^{-} / \mathrm{cm}^{2}\right) .{ }^{19}$ This was verified experimentally by ensuring the intensity in the $\mathrm{P}(2 p)$ region had decreased to $75 \%$ of the value measured after $\mathrm{Pt}\left(\mathrm{PF}_{3}\right)_{4}$ adsorption, and before the onset of electron irradiation.

Figures 4(a) and 4(b) show the spectral evolution of the $\mathrm{Pt}(4 f), \mathrm{P}(2 p)$, and $\mathrm{F}(1 s)$ regions as a function of annealing temperature for $\mathrm{Pt}\left(\mathrm{PF}_{3}\right)_{4}$ films initially exposed to a comparatively low $\left(2.39 \times 10^{+15} \mathrm{e}^{-} / \mathrm{cm}^{2}\right)$ and high $\left(8.32 \times 10^{+16}\right.$ $\mathrm{e}^{-} / \mathrm{cm}^{2}$ ) electron fluence at $-110^{\circ} \mathrm{C}$. Consequently, Fig. 4(a) shows the effect of substrate temperature on a film composed principally of $\mathrm{Pt}\left(\mathrm{PF}_{3}\right)_{3}$ species, while Fig. 4(b) illustrates how annealing affects an amorphous film that contains platinum, phosphorous, fluorine, and oxygen atoms $\left(\mathrm{PtP}_{3} \mathrm{~F}_{x} \mathrm{O}_{y}\right)$. Figure 5 shows the effect of annealing on various film characteristics, specifically the $\mathrm{Pt} / \mathrm{P}$ ratio, $\mathrm{F}$ signal, and $\operatorname{Pt}\left(4 f_{7 / 2}\right)$ binding energy for two $\operatorname{Pt}\left(\mathrm{PF}_{3}\right)_{4}$ films initially 

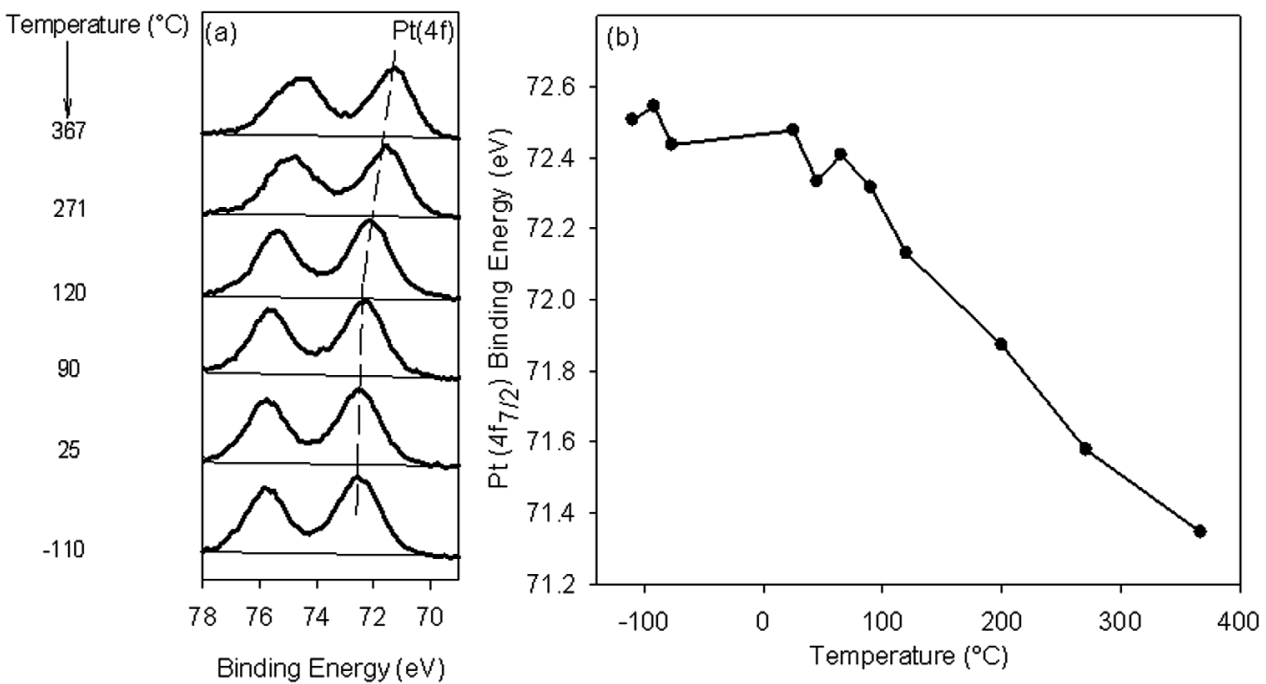

FIg. 2. (a) $\mathrm{Pt}(4 f) \mathrm{XP}$ region of a $2.5 \mathrm{~nm}$ thick EBID film of $\mathrm{MeCpPtMe}_{3}$ after being exposed to an electron fluence of $3.37 \times 10^{+16} \mathrm{e}^{-} / \mathrm{cm}^{2}$ at $-110^{\circ} \mathrm{C}$, and then annealed in stages up to $367^{\circ} \mathrm{C}$. (b) Variation in the $\mathrm{Pt}\left(4 f_{7 / 2}\right)$ XPS peak position for the same film.

exposed to a comparatively low $\left(6.24 \times 10^{+15} \mathrm{e}^{-} / \mathrm{cm}^{2}\right)$ and high $\left(3.31 \times 10^{+17} \mathrm{e}^{-} / \mathrm{cm}^{2}\right)$ electron fluence at $-110^{\circ} \mathrm{C}$.

For the film exposed to a comparatively low electron fluence, composed principally of $\mathrm{Pt}\left(\mathrm{PF}_{3}\right)_{3}$ species at $-110^{\circ} \mathrm{C}$, analysis of Figs. 4(a), 5(a), and 5(b) reveals that increasing substrate temperature produces a decrease in the concentration of phosphorous and fluorine atoms, while the $\mathrm{P} / \mathrm{F}$ ratio (not shown) remains relatively unchanged. These changes occur predominantly above $0{ }^{\circ} \mathrm{C}$ and give rise to a systematic increase in the $\mathrm{Pt} / \mathrm{P}$ ratio [Fig. 5(a)]. Collectively, these results support the idea that the principal effect of annealing is to facilitate the thermal desorption of intact $\mathrm{PF}_{3}$ ligands from the $\mathrm{Pt}\left(\mathrm{PF}_{3}\right)_{3}$ intermediate

$$
\mathrm{Pt}\left(\mathrm{PF}_{3}\right)_{3}(\text { ads })+\Delta \rightarrow \operatorname{Pt}\left(\mathrm{PF}_{3}\right)_{3-x}(\text { ads })+x \mathrm{PF}_{3}(\mathrm{~g}) \uparrow .
$$

Thus, the overall sequence of bond breaking steps for these films can be described by the following sequence:

$$
\begin{array}{r}
\mathrm{Pt}\left(\mathrm{PF}_{3}\right)_{4}(\mathrm{~g})+\mathrm{e}^{-} \rightarrow \mathrm{Pt}\left(\mathrm{PF}_{3}\right)_{3}(\text { ads })+\mathrm{PF}_{3}(\mathrm{~g}) \uparrow \\
\quad\left(\text { electron stimulated deposition at }-110^{\circ} \mathrm{C}\right),
\end{array}
$$

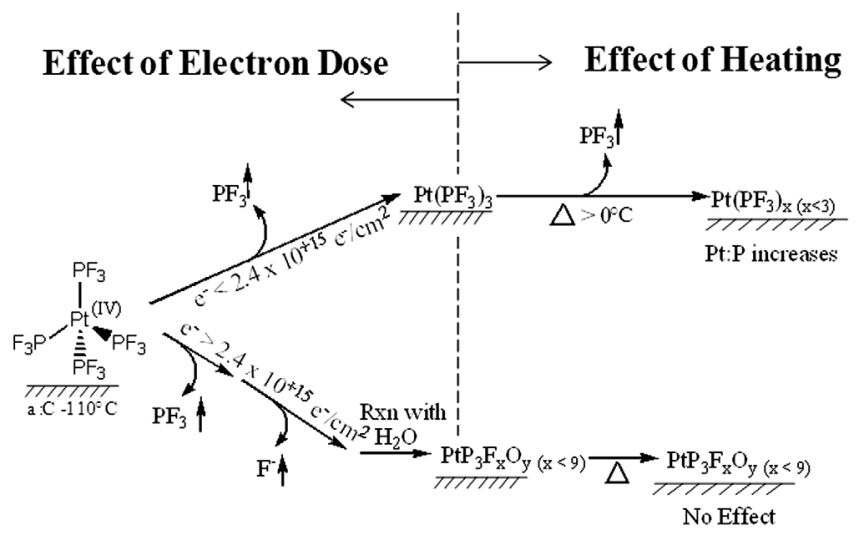

FIG. 3. Interplay between the effect of electron fluence and substrate temperature on the structure and elemental composition of $\mathrm{Pt}\left(\mathrm{PF}_{3}\right)_{4}$ films exposed to comparatively small (upper reaction sequence) and large (lower reaction sequence) electron doses.

$$
\begin{array}{r}
\mathrm{Pt}\left(\mathrm{PF}_{3}\right)_{3}(\text { ads })+\Delta \rightarrow \mathrm{Pt}\left(\mathrm{PF}_{3}\right)_{3-x}(\text { ads })+x \mathrm{PF}_{3}(\mathrm{~g}) \uparrow \\
\text { (thermally stimulated } \left.\mathrm{PF}_{3} \text { desorption above } 0{ }^{\circ} \mathrm{C}\right) .
\end{array}
$$

Since both steps involve $\mathrm{Pt}_{-} \mathrm{PF}_{3}$ bond cleavage, the overall process is analogous to the chemical vapor deposition
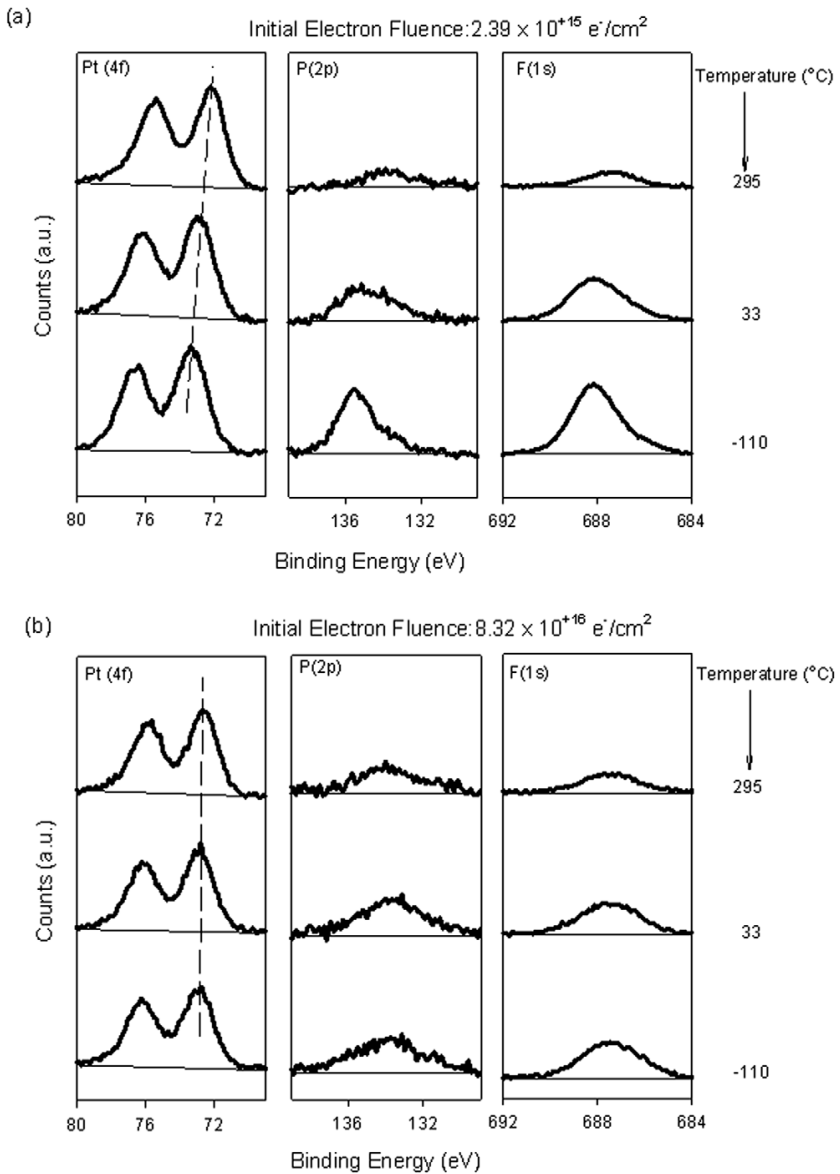

FIG. 4. Effect of annealing on the $\mathrm{Pt}(4 f), \mathrm{P}(2 p)$, and $\mathrm{F}(1 s) \mathrm{XP}$ regions for $0.3 \mathrm{~nm}$ thick films of $\mathrm{Pt}\left(\mathrm{PF}_{3}\right)_{4}$ exposed to electron fluences of (a) $2.39 \times 10^{+15} \mathrm{e}^{-} / \mathrm{cm}^{2}$ and (b) $8.32 \times 10^{+16} \mathrm{e}^{-} / \mathrm{cm}^{2}$. Films were initially irradiated at $-110^{\circ} \mathrm{C}$ and then annealed in stages up to $295^{\circ} \mathrm{C}$. 

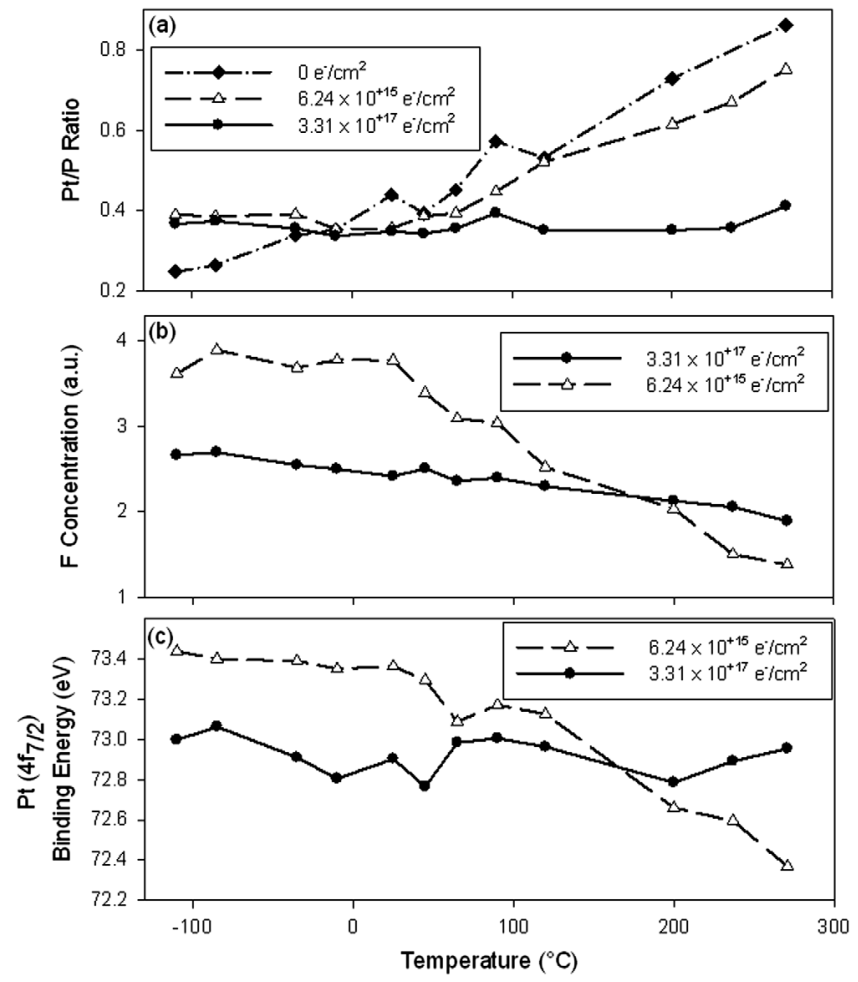

FIG. 5. Effect of substrate temperature on (a) platinum to phosphorus (Pt:F) ratio, (b) fluorine concentration, and (c) the $\operatorname{Pt}\left(4 f_{7 / 2}\right)$ binding energy. EBID films were created by irradiating $0.3 \mathrm{~nm}$ thick films of $\mathrm{Pt}\left(\mathrm{PF}_{3}\right)_{4}$ at $-110^{\circ} \mathrm{C}$ to electron fluences of $0 \mathrm{e}^{-} / \mathrm{cm}^{2}$ (black diamonds), $6.24 \times 10^{+15} \mathrm{e}^{-} / \mathrm{cm}^{2}$ (white triangles), and $3.31 \times 10^{+17} \mathrm{e}^{-} / \mathrm{cm}^{2}$ (black circles) prior to annealing.

(CVD) of $\mathrm{Pt}$ from $\mathrm{Pt}\left(\mathrm{PF}_{3}\right)_{4}$ which occurs exclusively by $\mathrm{Pt}_{-} \mathrm{PF}_{3}$ bond cleavage. This can be reasonably inferred because CVD of $\mathrm{Pt}\left(\mathrm{PF}_{3}\right)_{4}$ can produce pure Pt films. ${ }^{35}$ Consistent with the idea that the EBID and CVD processes are analogous under these conditions, Fig. 5(a) shows that the change in $\mathrm{Pt} / \mathrm{P}$ ratio above room temperature for films composed of $\mathrm{Pt}\left(\mathrm{PF}_{3}\right)_{3}$ species is very similar to the one observed when a film composed of $\mathrm{Pt}\left(\mathrm{PF}_{3}\right)_{4}$ is annealed from $-110^{\circ} \mathrm{C}$ in the absence of any initial electron beam irradiation [solid diamonds in Fig. 5(a)].

In addition to the thermally induced changes in chemical composition, the $\operatorname{Pt}\left(4 f_{7 / 2}\right)$ binding energy was observed to decrease when films initially composed of $\mathrm{Pt}\left(\mathrm{PF}_{3}\right)_{3}$ at $-110^{\circ} \mathrm{C}$ were annealed above room temperature, as shown in Fig. 4(a) and plotted in Fig. 5(c). Analogous to the behavior of films created from $\mathrm{MeCpPtMe}_{3}$, this change in binding energy is indicative of an increase in metallic character.

For the amorphous films formed when $\mathrm{Pt}\left(\mathrm{PF}_{3}\right)_{4}$ films were exposed to a larger electron fluence and which contain platinum, phosphorous, fluorine, and oxygen atoms $\left(\mathrm{PtP}_{3} \mathrm{~F}_{x} \mathrm{O}_{y}\right)$, analysis of Fig. 5 and a comparison between Figs. 4(a) and 4(b) reveals that the effect of substrate temperature differs significantly from the behavior of the $\mathrm{Pt}\left(\mathrm{PF}_{3}\right)_{3}$ species. The most obvious difference is in the behavior of the phosphorous and fluorine signals in Fig. 4(b) which are relatively unaffected by increasing the substrate temperature in marked contrast to Fig. 4(a). Consequently, the Pt/P ratio for these films remains largely unchanged except for a slight increase at the highest temperatures. This lack of compositional dependence on substrate temperature can be rationalized by the fact that prolonged electron irradiation decomposes the $\mathrm{PF}_{3}$ ligands within the $\mathrm{Pt}\left(\mathrm{PF}_{3}\right)_{3}$ intermediate due to $\mathrm{P}-\mathrm{F}$ bond cleavage effectively removing the thermal route for phosphorous or fluorine atoms to be removed by $\mathrm{PF}_{3}$ ejection as shown by

$$
\mathrm{PtP}_{3} \mathrm{~F}_{x} \mathrm{O}_{Y} \text { (ads) }+\Delta \rightarrow \text { No change. }
$$

One interesting consequence of this difference in behavior is manifested in Fig. 5(b). This reveals that although a $\operatorname{Pt}\left(\mathrm{PF}_{3}\right)_{4}$ film initially exposed to a large electron fluence at $-110^{\circ} \mathrm{C}$ has a lower fluorine atom concentration due to the effects of P-F bond cleavage, the fluorine content of a $\mathrm{Pt}\left(\mathrm{PF}_{3}\right)_{4}$ film initially exposed to a much lower initial electron fluence at $-110^{\circ} \mathrm{C}$ is actually lower at substrate temperatures greater than $200^{\circ} \mathrm{C}$, due to thermal desorption of $\mathrm{PF}_{3}$ ligands. This is a consequence of the fact that the fluorine and phosphorous atoms in the amorphous films that form at a higher electron fluence are essentially "locked" or trapped in the film. Consequently, for platinum atoms encased in the phosphorous rich matrix that forms at a higher electron fluence, Fig. 5(c) shows that there is no increase in metallic character as the substrate temperature increases.

\section{C. $\mathrm{W}(\mathrm{CO})_{6}$}

The electron stimulated reactions of $\mathrm{W}(\mathrm{CO})_{6}$ can be described by an initial step which involves the desorption of multiple CO ligands from the parent molecule to produce partially decarbonylated species $\left[\mathrm{W}_{x}(\mathrm{CO})_{y}\right]$. Once formed, these species undergo electron stimulated decomposition ultimately producing oxidized tungsten atoms embedded in a carbon matrix, $\left(\mathrm{W}_{x} \mathrm{O}_{b}\right) \mathrm{C}_{\text {ads }}$ (Fig. 6). ${ }^{20}$ To ensure that all of the parent $\mathrm{W}(\mathrm{CO})_{6}$ molecules had reacted prior to annealing, films were exposed to an electron fluence in excess of the value where no more $\mathrm{CO}$ was being evolved as determined by mass spectrometry. This electron fluence corresponds to $\approx 1 \times 10^{+17} \mathrm{e}^{-} / \mathrm{cm}^{2} .20$

Figures 7 (a) and 7(b) compare the effect of increasing substrate temperature on $\mathrm{W}(\mathrm{CO})_{6}$ films initially exposed to an electron fluence of $1.00 \times 10^{+17} \mathrm{e}^{-} / \mathrm{cm}^{2}$ and $4.49 \times 10^{+17}$ $\mathrm{e}^{-} / \mathrm{cm}^{2}$, respectively. This corresponds to studying the effect of annealing on [Fig. 7(a)] a film composed of a mixture of partially decarbonylated tungsten $\mathrm{W}_{x}(\mathrm{CO})_{y}$ species as well

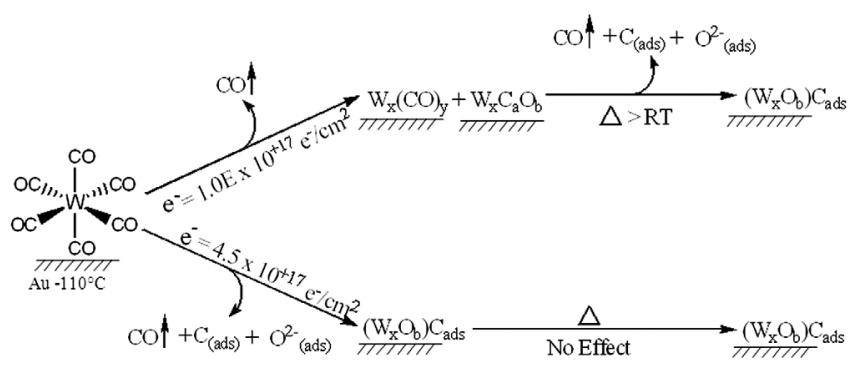

FIG. 6. Effect of substrate temperature on the structure and elemental composition of $\mathrm{W}(\mathrm{CO})_{6}$ films exposed to comparatively small (upper reaction sequence) and large (lower reaction sequence) electron doses. 

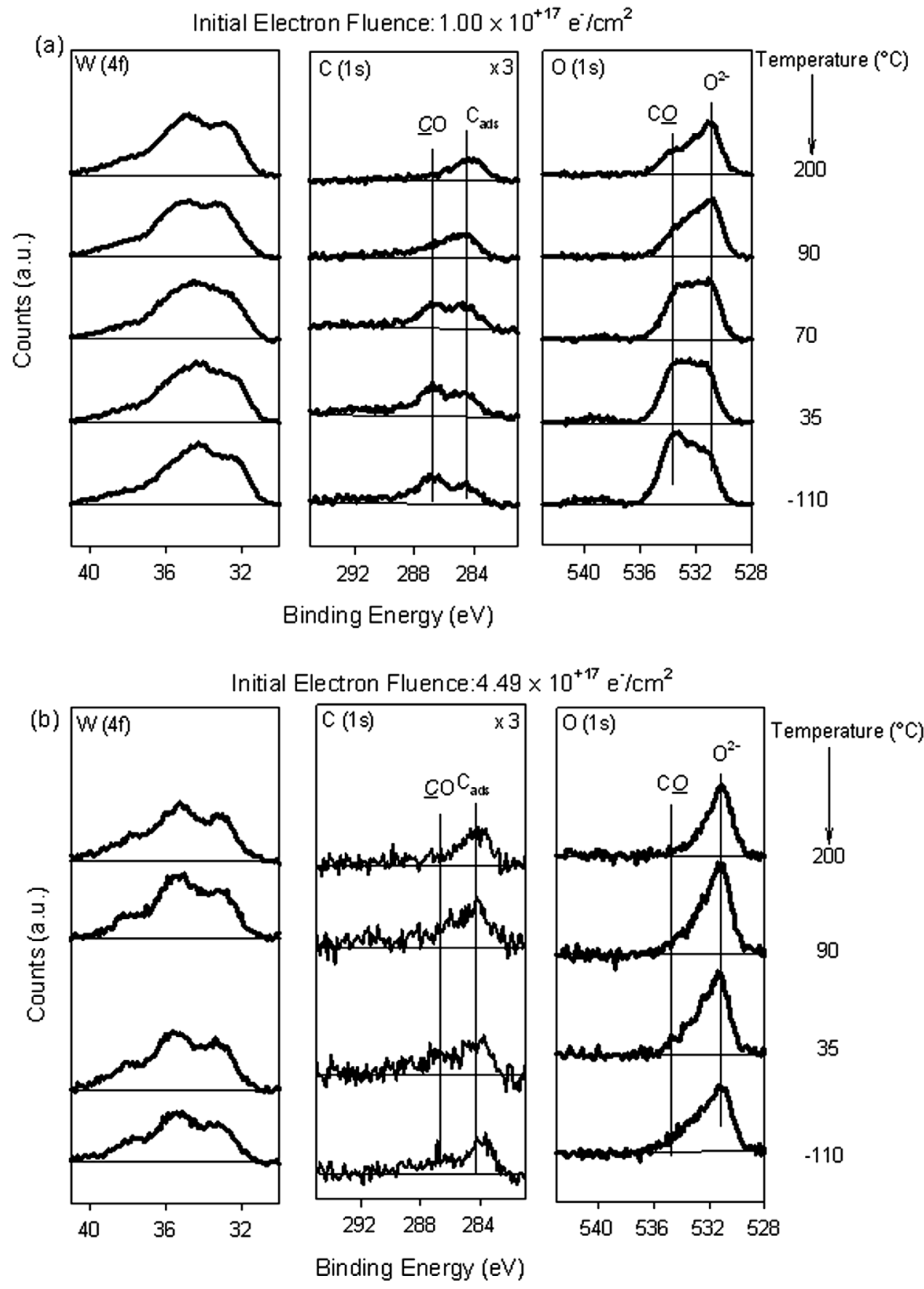

FIG. 7. Evolution of the $\mathrm{W}(4 f), \mathrm{C}(1 \mathrm{~s})$, and $\mathrm{O}(1 \mathrm{~s}) \mathrm{XP}$ regions for $1.5 \mathrm{~nm}$ thick films of $\mathrm{W}(\mathrm{CO})_{6}$ exposed to electron fluences of (a) $1.00 \times 10^{+17} \mathrm{e}^{-} / \mathrm{cm}^{2}$ and, $(\mathrm{b})$ $4.49 \times 10^{+17} \mathrm{e}^{-} / \mathrm{cm}^{2}$ at $-110^{\circ} \mathrm{C}$ and then heated in stages to $200^{\circ} \mathrm{C}$.

as some oxidized tungsten atoms encased in a carbonaceous matrix, $\left(\mathrm{W}_{x} \mathrm{O}_{b}\right) \mathrm{C}_{\mathrm{ads}}$, and [Fig. 7(b)] a film that contains almost exclusively oxidized tungsten atoms encased in a carbonaceous matrix, $\left(\mathrm{W}_{x} \mathrm{O}_{b}\right) \mathrm{C}_{\text {ads }}$.

Analysis of the spectra shown in Fig. 7(a) reveals, for annealing temperatures $>25^{\circ} \mathrm{C}$, there is a decrease in signal intensity within the $\mathrm{O}(1 s)$ and $\mathrm{C}(1 s)$ regions at 534 and $287.5 \mathrm{eV}$, respectively, corresponding to peaks associated with CO ligands. ${ }^{36}$ The loss of these spectral features indicates that $\mathrm{CO}$ can desorb at substrate temperatures $>25^{\circ} \mathrm{C}$. Indeed, evidence of thermal $\mathrm{CO}$ desorption from partially decarbonylated metal carbonyls has been observed in previous temperature programmed desorption studies of $\mathrm{Fe}(\mathrm{CO})_{5}$ and $\mathrm{Ni}(\mathrm{CO})_{4}$ (Refs. 37-40), where films were electron beam irradiated at lower substrate temperatures under UHV conditions and then heated. Analysis of the W(4f) region indicates that when $\mathrm{CO}$ desorbs from the film, there is a slight increase in the spectral intensity at $\approx 34.9 \mathrm{eV}$ within the $\mathrm{W}(4 f)$ region as well as the concentration of adsorbed carbon atoms $\left(\mathrm{C}_{\mathrm{ads}}\right)$ and oxide species $\left(\mathrm{O}^{2-}\right)$. All of these spectral changes indicate that thermal desorption of $\mathrm{CO}$ from $\mathrm{W}_{x}(\mathrm{CO})_{y}$ species competes with ligand (CO) decomposition, the latter adding to the concentration of oxidized tungsten atoms encased in the carbonaceous matrix $\left[\left(\mathrm{W}_{x} \mathrm{O}_{b}\right) \mathrm{C}_{\mathrm{ads}}\right]$. 
Thus, these thermal effects on partially decarbonylated species can be summarized as (see Fig. 6)

$$
\mathrm{W}_{x}(\mathrm{CO})_{y}(\mathrm{ads})+\Delta \rightarrow\left(\mathrm{W}_{x} \mathrm{O}_{b}\right) \mathrm{C}_{\mathrm{ads}}+\mathrm{CO} \uparrow(\mathrm{g}) .
$$

This competition between $\mathrm{CO}$ desorption and decomposition above room temperature is consistent with the behavior of molecular $\mathrm{CO}$ adsorbed directly onto $\mathrm{W}$ surfaces at $-173^{\circ} \mathrm{C}$ and then annealed in a stepwise fashion to $127^{\circ} \mathrm{C} .^{41}$

For $\mathrm{W}(\mathrm{CO})_{6}$ films exposed to a larger electron fluence the partially decarbonylated $\mathrm{W}_{x}(\mathrm{CO})_{y}$ species undergo electron stimulated decomposition and the film converts to one that is composed of oxidized tungsten atoms embedded in a carbon matrix $\left(\mathrm{W}_{x} \mathrm{O}_{b}\right) \mathrm{C}_{\text {ads }}$. This is the situation in Fig. $7(\mathrm{~b})$ for a $\mathrm{W}(\mathrm{CO})_{6}$ film exposed to an electron fluence of $4.49 \times 10^{+17}$ $\mathrm{e}^{-} / \mathrm{cm}^{2}$. In contrast to Fig. 7(a) analysis of the W(4f), C(1s), and $\mathrm{O}(1 s)$ regions of Fig. 7(b) shows that increasing substrate temperature has little or no effect on this film's chemical composition or bonding, analogous to the behavior of $\operatorname{Pt}\left(\mathrm{PF}_{3}\right)_{4}$ molecules which had been initially exposed to a large initial fluence [see Figs. 4(b) and 5]. This similarity in behavior between $\mathrm{Pt}\left(\mathrm{PF}_{3}\right)_{4}$ and $\mathrm{W}(\mathrm{CO})_{6}$ is a reflection of the fact that for a sufficiently high electron fluence all of the ligands have been decomposed by multiple electron adsorbate interactions and, consequently, there is no opportunity for any subsequent thermally induced ligand desorption and corresponding change in chemical composition. All of the oxidized tungsten atoms are essentially trapped within the amorphous carbonaceous matrix and increasing the substrate temperature has no effect (see Fig. 6)

$$
\left(\mathrm{W}_{x} \mathrm{O}_{b}\right) \mathrm{C}_{\mathrm{ads}}+\Delta \rightarrow \text { no change. }
$$

\section{Broader implications}

XPS data have been used to probe the effect of temperature on the fate of different species formed by electron irradiation of $\mathrm{MeCpPtMe}_{3}, \mathrm{~W}(\mathrm{CO})_{6}$, and $\mathrm{Pt}\left(\mathrm{PF}_{3}\right)_{4}$. This information can also serve as the basis to understand temperature dependent changes in film composition when deposition occurs continuously and in the presence of a constant flux of electrons (i.e., typical EBID experiments conducted in electron microscopes).

For precursors such as $\mathrm{MeCpPtMe}_{3}$, where our previous studies have shown no evidence of an identifiable surface bound intermediate, ${ }^{16,18}$ temperature and electron beam flux should not influence the film's chemical composition. This is consistent with the experimental data shown in Fig. 1(a) and also with recent results obtained by Mulders et al. [Fig. 1(b)], who studied the composition of EBID films created from $\mathrm{MeCpPtMe}_{3}$ in a SEM as a function of substrate temperature in the range $25^{\circ} \mathrm{C}$ to $360^{\circ} \mathrm{C}^{15}$ Indeed, despite the different deposition conditions and analytical techniques (XPS in the present study, and EDS in the study by Mulders), a comparison of Figs. 1(a) and 1(b) shows that the chemical composition of the EBID materials is very similar in the two studies. This insensitivity to deposition conditions also supports the idea that the comparatively low incident electron energies
$(500 \mathrm{eV})$ used in the present study serve as a good proxy for the effects of the significantly higher electron energies $(>1 \mathrm{keV})$ used to initiate EBID in electron microscopes. Moreover, the lack of a surface bound intermediate in the electron stimulated decomposition of $\mathrm{MeCpPtMe}_{3}$ helps to rationalize the empirical observation that the platinum content in nanostructures created by EBID from $\mathrm{MeCpPtMe}_{3}$ are invariably observed to be in the range of $10-20 \%$ despite the range of different instruments and gas phase conditions used for deposition, and the variety of analytical techniques used to determine composition. ${ }^{3,8,42}$ This insensitivity to deposition parameters coupled with the incorporation of all of the carbon atoms in the $\mathrm{Cp}$ ligands as well as two of the $\mathrm{Pt}^{-} \mathrm{CH}_{3}$ carbon atoms into the deposit means that the prospects for creating pure or even platinum rich deposits from this precursor by varying deposition conditions are poor.

For the other two precursors, $\mathrm{W}(\mathrm{CO})_{6}$ and $\operatorname{Pt}\left(\mathrm{PF}_{3}\right)_{4}$, the agreement between our UHV results and those obtained in more typical EBID studies is more qualitative due to the presence of surface intermediates which can remain either partially or completely decomposed depending on the deposition conditions and the rate of the electron and/or thermal stimulated decomposition pathways. However, our experimental data still enable us to rationalize the effects of increasing substrate temperature on composition. Thus, for $\mathrm{W}(\mathrm{CO})_{6}$, the principle reason why Mulders observed an increase in tungsten content as the substrate temperature increased from $0-150^{\circ} \mathrm{C}$ can be ascribed to the onset of thermally assisted $\mathrm{CO}$ desorption from partially decarbonylated $\mathrm{W}_{x}(\mathrm{CO})_{y}$ species which can occur above room temperature [see Fig. 7(a)]. Conversely, when deposition is performed at lower substrate temperatures where thermal desorption of $\mathrm{CO}$ from $\mathrm{W}_{x}(\mathrm{CO})_{y}$ species is not possible, more of the carbon and oxygen become trapped within the deposit.

For $\mathrm{Pt}\left(\mathrm{PF}_{3}\right)_{4}$ the overall fate of the molecule can be described by Fig. 8 , in which the initial electron stimulated deposition event involves the ejection of a single $\mathrm{PF}_{3}$ ligand, while the fate of the $\operatorname{Pt}\left(\mathrm{PF}_{3}\right)_{3}$ intermediate thus formed is sensitive to the deposition conditions. High substrate temperatures and low electron fluxes will favor thermal decomposition of the $\mathrm{Pt}\left(\mathrm{PF}_{3}\right)_{3}$ intermediate leading to $\mathrm{PF}_{3}$ ejection, while comparatively low substrate temperatures and high electron fluxes will favor further electron stimulated

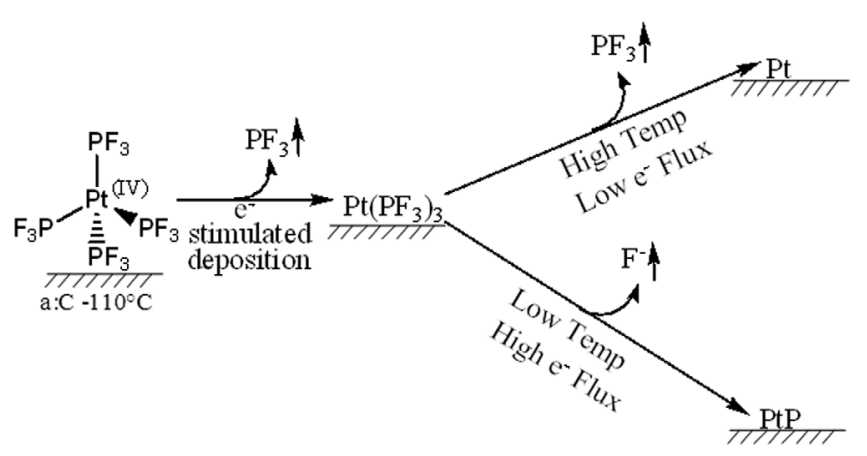

FIG. 8. Summary of the effect that different deposition conditions (electron fluence and substrate temperature) will have on the fate of $\operatorname{Pt}\left(\mathrm{PF}_{3}\right)_{4}$ molecules dissociated during EBID. 
decomposition of the $\mathrm{Pt}\left(\mathrm{PF}_{3}\right)_{3}$ intermediate which proceeds via $\mathrm{P}-\mathrm{F}$ bond cleavage and $\mathrm{F}^{-}$ejection. Consequently, under conditions where the electron flux is held constant and the substrate temperature increases we would expect to increasingly favor thermal over electron stimulated decomposition of $\mathrm{Pt}\left(\mathrm{PF}_{3}\right)_{3}$ intermediate. This provides a rationale for why the $\mathrm{Pt} / \mathrm{P}$ ratio in films deposited from $\mathrm{Pt}\left(\mathrm{PF}_{3}\right)_{4}$ by Wang et al. in an Auger system increased significantly as the substrate temperature increased from $25-100{ }^{\circ} \mathrm{C} .{ }^{14}$ In contrast to platinum and phosphorous atoms, however, fluorine atoms can be removed continuously by electron irradiation. This is the reason why deposits can be created from $\mathrm{Pt}\left(\mathrm{PF}_{3}\right)_{4}$ that contain only Pt and P atoms. ${ }^{11,14,22}$

In addition to the effect that substrate temperature has on film composition, our results show that the binding energy of platinum atoms in the $\mathrm{Pt}(4 f)$ region decreases systematically as the substrate temperature increases above $0^{\circ} \mathrm{C}$ [Figs. 2 and 5(c)], an effect which is consistent with an increase in metallic character. For films created from $\mathrm{MeCpPtMe}_{3}$, such an effect can only be due to an increase in mobility and nucleation of $\mathrm{Pt}$ atoms formed by the deposition process since there are no corresponding changes in film composition. The situation is more complex for films created from $\mathrm{Pt}\left(\mathrm{PF}_{3}\right)_{4}$ because increasing temperature also changes the film's composition. Since there was no temperature dependent change in the binding energy of platinum atoms in films where extensive $\mathrm{PF}_{3}$ ligand decomposition had occurred [Fig. 5(b)], our results suggest that the principle reason for the increase in metallic character in this system is due to $\mathrm{PF}_{3}$ ligand removal. Regardless, our results point toward the beneficial effects that increasing substrate temperature (either during deposition or as a post-deposition technique) can have on the conductivity of EBID deposits even if there is no change in composition. Indeed, several studies have shown that post-deposition annealing improves the conductivity of EBID deposits created from $\mathrm{MeCpPtMe}_{3}$ and $\mathrm{Pt}\left(\mathrm{PF}_{3}\right)_{4}{ }^{8,13,21}$

The success of this UHV approach in rationalizing some of the effects of deposition conditions on EBID materials relies on its ability to focus on the surface species and bond breaking processes that represent one important aspect of the EBID process. It is important, however, to keep in mind that other factors also contribute to the overall chemical composition of EBID materials created under steady state deposition conditions; these include the effects of electron induced heating, diffusion, and the role played by contaminant gases such as $\mathrm{H}_{2} \mathrm{O}$ which are often present in electron microscopes at significant partial pressures. ${ }^{27,43-45}$ For example, the presence of water vapor can remove carbon atoms from deposits through the formation of volatile carbon species such as $\mathrm{CO}$ and $\mathrm{CO}_{2}$. These processes are mediated by reactive oxygen species (such as oxygen atoms) formed by electron induced decomposition of water molecules adsorbed to the surface. However, these same species can also facilitate metal atom oxidation. In contrast to the possible beneficial and/or detrimental effects of water vapor on the quality of EBID deposits, the presence of hydrocarbons can only negatively impact purity by adding to the burden of deposited carbon. Another factor which must be considered in translating the effect of substrate temperature on chemical composition determined from the UHV experiments described in this study to experiments conducted under dynamic, steady state conditions is the upper temperature limit (or ceiling) imposed by the onset of conformal CVD deposition involving the precursor. For example, in the case of $\mathrm{MeCpPtMe}_{3}$, spontaneous deposition was observed in electron microscopes at $360{ }^{\circ} \mathrm{C} ;{ }^{15}$ consequently, EBID experiments using this precursor should not be conducted at substrate temperatures at or even slightly below this temperature, to ensure the spatial integrity and specificity of the deposit.

\section{SUMMARY AND CONCLUSIONS}

The effect of electron fluence and substrate temperature on the chemical composition and metallic character in EBID films has been examined with a UHV surface science approach using XPS to monitor changes in composition and bonding within nanometer scale thick films of precursor molecules initially exposed to different electron fluence at $-110^{\circ} \mathrm{C}$ and then subsequently annealed. For $\mathrm{MeCpPtMe}_{3}$, variations in the substrate temperature or electron fluence do not change the film's composition because electron stimulated deposition decomposes the metal-ligand architecture without the formation of any stable surface intermediate. Increasing substrate temperature does, however, improve the mobility of platinum atoms encased within the carbonaceous matrix that forms during deposition positively impacting the extent of metal-metal bonding. For $\mathrm{Pt}\left(\mathrm{PF}_{3}\right)_{4}$ films initially exposed to a comparatively small electron fluence, annealing leads to desorption of intact $\mathrm{PF}_{3}$ ligands from $\mathrm{Pt}\left(\mathrm{PF}_{3}\right)_{3}$ intermediates formed during the initial deposition event. This also facilitates an increase in metal-metal bonding at elevated substrate temperatures. In contrast, for a larger initial electron fluence, electron stimulated P-F bond cleavage within $\mathrm{Pt}\left(\mathrm{PF}_{3}\right)_{3}$ species creates platinum atoms trapped in a matrix of phosphorous and fluorine atoms whose composition and metallic character remain invariant to subsequent increases in substrate temperature. For $\mathrm{W}(\mathrm{CO})_{6}$, thermally stimulated reactions of partially decarbonylated $\mathrm{W}_{x}(\mathrm{CO})_{y}$ species formed during the initial electron induced deposition event occur above room temperature and involve a competition between $\mathrm{CO}$ desorption and decomposition. In summary, this study highlights how a more detailed understanding of the intermediates and bond breaking processes involved in EBID can help to rationalize the influence of deposition parameters on film properties.

${ }^{1}$ W. F. van Dorp and C. W. Hagen, J. Appl. Phys. 104, 081301 (2008).

${ }^{2}$ S. J. Randolph, J. D. Fowlkes, and P. D. Rack, Crit. Rev. Solid State Mater. Sci. 31, 55 (2006).

${ }^{3}$ I. Utke, P. Hoffman, and J. Melngailis, J. Vac. Sci. Technol. B 26, 1197 (2008).

${ }^{4}$ N. Silvis-Cividjian, C. W. Hagen, P. Kruit, M. A. v.d. Stam, and H. B. Groen, Appl. Phys. Lett. 82, 3514 (2003).

${ }^{5}$ A. Botman, M. Hesselberth, and J. J. L. Mulders, J. Vac. Sci. Technol. B 26, 2464 (2008).

${ }^{6}$ A. Botman, J. J. L. Mulders, R. Weemaes, and S. Mentink, Nanotechnology 17, 3779 (2006). 
${ }^{7}$ M. Takeguchi, M. Shimojo, and K. Furuya, Appl. Phys. A 93, 439 (2008).

${ }^{8}$ A. Botman, M. Hesselberth, and J. J. L. Mulders, Microelectron. Eng. 85, 1139 (2008).

${ }^{9}$ J. Li, M. Toth, V. Tileli, K. A. Dunn, C. J. Lobo, and B. L. Thiel, Appl. Phys. Lett. 93, 023130 (2008).

${ }^{10}$ P. C. Hoyle, J. R. A. Cleaver, and H. Ahmed, J. Vac. Sci. Technol. B 14, 662 (1996).

${ }^{11}$ J. Barry, M. H. Ervin, J. Molstad, A. Wickenden, T. Brintlinger, P. Hoffman, and J. Meingailis, J. Vac. Sci. Technol. B 24, 3165 (2006).

${ }^{12}$ K. T. Kohlmann-von Platen, L. M. Buchmann, H. C. Petzold, and W. H. Brunger, J. Vac. Sci. Technol. B 10, 2690 (1992).

${ }^{13}$ H. W. P. Koops, C. Schossler, A. Kaya, and M. Weber, J. Vac. Sci. Technol. B 14, 4105 (1996).

${ }^{14}$ S. Wang, Y.-M. Sun, Q. Wang, and J. M. White, J. Vac. Sci. Technol. B 22, 1803 (2004).

${ }^{15}$ J. J. L. Mulders, L. M. Belova, and A. Riazanova, Nanotechnology 22, 055302 (2011).

${ }^{16}$ J. D. Wnuk, J. M. Gorham, S. G. Rosenberg, W. F. van Dorp, T. E. Madey, C. W. Hagen, and D. H. Fairbrother, J. Phys. Chem. C 113, 2487 (2009).

${ }^{17}$ J. D. Wnuk, J. M. Gorham, S. G. Rosenberg, W. F. van Dorp, T. E. Madey, C. W. Hagen, and D. H. Fairbrother, J. Appl. Phys. 107, 054301 (2010).

${ }^{18}$ J. D. Wnuk, S. G. Rosenberg, J. M. Gorham, W. F. van Dorp, C. W. Hagen, and D. H. Fairbrother, Surf. Sci. 605, 257 (2011).

${ }^{19}$ K. Landheer, S. G. Rosenberg, L. Bernau, P. Swiderek, I. Utke, C. W. Hagen, and D. H. Fairbrother, J. Phys. Chem. C 115, 17452 (2011).

${ }^{20}$ S. G. Rosenberg, M. Barclay, and D. H. Fairbrother, "Electron interactions with nanoscale thin films of tungsten hexacarbonyl-W(CO) 6 ," Phys. Chem. Chem. Phys. (submitted).

${ }^{21}$ M. H. Ervin, D. Chang, B. Nichols, A. Wickenden, J. Barry, and a. Melngailis, J. Vac. Sci. Technol. B 25, 2250 (2007).

${ }^{22}$ A. Botman, D. A. M. de Winter, and J. J. L. Mulders, J. Vac. Sci. Technol. B 26, 2460 (2008).

${ }^{23}$ H. Schroder, K. L. Kompa, D. Masci, and I. Gianinoni, Appl. Phys. A 38, 227 (1985).

${ }^{24}$ I. Sychugov, Y. Nakayama, and K. Mitsuishi, J. Phys. Chem. C 113, 21516 (2009).
${ }^{25}$ W. F. van Dorp, B. van Someren, C. W. Hagen, P. Kruit, and P. A. Crozier, J. Vac. Sci. Technol. B 24, 618 (2006).

${ }^{26}$ W. F. van Dorp, C. W. Hagen, P. A. Crozier, and P. Kruit, Nanotechnology 19, 225305 (2008).

${ }^{27}$ F. Porrati, R. Sachser, and M. Huth, Nanotechnology 20, 195301 (2009).

${ }^{28}$ H. W. P. Koops, R. Weiel, D. P. Kern, and T. H. Baum, J. Vac. Sci. Technol. B 6, 477 (1988).

${ }^{29}$ S. Frabboni, G. C. Gazzadi, L. Felisari, and A. Spessot, Appl. Phys. Lett. 88, 213116 (2006).

${ }^{30}$ S. Frabboni, G. C. Gazzadi, and A. Spessot, Physica E: Low-Dimens. Syst. Nanostruct. 37, 265 (2007).

${ }^{31}$ W. F. van Dorp, J. D. Wnuk, J. M. Gorham, D. H. Fairbrother, T. E. Madey, and C. W. Hagen, J. Appl. Phys. 106, 074903 (2009).

${ }^{32}$ P. D. Rack, S. J. Randolph, Y. Deng, J. D. Fowlkes, Y. Choi, and D. C. Joy, Appl. Phys. Lett. 82, 2326 (2003).

${ }^{33}$ J. F. Moulder, W. F. Stickle, P. E. Sobol, and K. D. Bomben, Handbook of $X$-ray Photoelectron Spectroscopy (Physical Electronics USA, Inc., Chanhassen, 1995).

${ }^{34}$ S. Tanuma, C. J. Powell, and D. R. Penn, Surf. Interface Anal. 17, 911 (1991).

${ }^{35}$ M. J. Rand, J. Electrochem. Soc. 120, 686 (1973).

${ }^{36}$ F. Zaera, J. Phys. Chem. 96, 4609 (1992).

${ }^{37}$ M. A. Henderson, R. D. Ramsier, and J. T. Yates, J. Vac. Sci. Technol. A 9, 1563 (1991).

${ }^{38}$ M. A. Henderson, R. D. Ramsier, and J. T. Yates, Surf. Sci. 259, 173 (1991).

${ }^{39}$ R. D. Ramsier, M. A. Henderson, and J. T. Yates, Surf. Sci. 257, 9 (1991).

${ }^{40}$ C. Hauchard, C. Pepin, and P. Rowntree, Langmuir 21, 9166 (2005).

${ }^{41}$ E. Umbach and D. Menzel, Surf. Sci. 135, 199 (1983).

${ }^{42}$ H. W. Koops, A. Kaya, and M. Weber, J. Vac. Sci. Technol. B 13, 2400 (1995).

${ }^{43}$ F. Porrati, R. Sachser, C. H. Schwalb, A. S. Frangakis, and M. Huth, J. Appl. Phys. 109, 063715 (2011).

${ }^{44}$ A. Botman, C. W. Hagen, J. Li, B. L. Thiel, K. A. Dunn, J. J. L. Mulders, S. J. Randolph, and M. Toth, J. Vac. Sci. Technol. B 27, 2759 (2009).

${ }^{45}$ J. T. Li, M. Toth, K. A. Dunn, and B. L. Thiel, J. Appl. Phys. 107, 103540 (2010). 